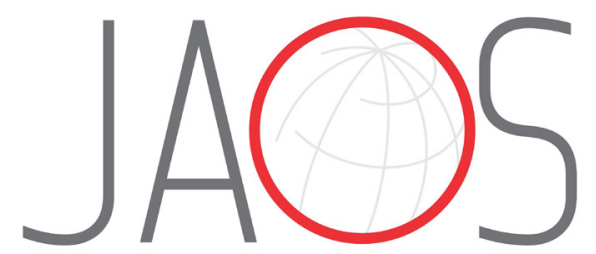

JOURNAL OF APPLIED ORAL SCIENCE

\title{
Comparison of rRNA-based reverse transcription PCR and rDNA-based PCR for the detection of streptococci in root canal infections
}

\section{Abstract}

Laís Cunha PRADO1

Giulio GAVINI

Amanda da Costa SILVEIRA ${ }^{1}$

Vitor Cesar NAKAMURA ${ }^{1}$

Marcia Pinto Alves MAYER ${ }^{2}$

Ericka Tavares PINHEIRO ${ }^{1}$
Submitted: October 8, 2018 Modification: February 13, 2019

Accepted: February 26, 2019

Corresponding address: Ericka T. Pinheiro

Endodontics Course - Restorative Dentistry Deparment - School of Dentistry Universidade de São Paulo Av. Prof. Lineu Prestes, 2227 - Cidade Universitária 05508-000 - São Paulo - SP - Brasil. Phone: +551130917841 e-mail: erickapinheiro@usp.br
Objective: The rDNA-based method is unable to distinguish between alive and dead cells. Alternatively, bacterial viability can be assessed by molecular methods based on ribosomal RNA (rRNA). Therefore, this study aimed to detect viable streptococci in root canal samples using rRNA-based reverse transcription polymerase chain reaction (RT-PCR), compared to an rDNAbased PCR assay. Methodology: Microbiological root canal samples were obtained from 32 teeth with primary endodontic infections before (S1) and after chemomechanical preparation (S2), and after removal of intracanal medication (S3). RNA and DNA were extracted, and complementary DNA (cDNA) was synthesized from RNA using RT reaction. cDNA and genomic DNA were subjected to PCR with primers complementary to the $16 \mathrm{~S}$ rRNA sequences of Streptococcus spp. McNemar's test was used to compare the detection rate of both assays $(P<0.05)$. Results: Streptococci were detected in $28.12 \%$ (9/32) and $37.5 \%(12 / 32)$ of S1 samples using rRNA- and rDNAbased PCR assays, respectively. In contrast, they were detected in only $6.25 \%$ (2/32) of S2 samples using rRNA-based RT-PCR, compared to $15.62 \%$ (5/32) using rDNA-based PCR. Finally, in S3 samples, streptococci were not detected by rRNA, whereas rDNA-based PCR still detected the bacteria in $12.5 \%(4 / 32)$ of the samples. The total number of PCR-positive reactions in the rDNA-based PCR was higher than in the rRNA-based assay $(P<0.05)$. Conclusions: The rRNA-based RT-PCR showed a lower detection rate of streptococci when compared to the rDNA-based PCR, suggesting that the latter may have detected dead cells of streptococci in root canal samples.

Keywords: Streptococcus. Reverse transcription polymerase chain reaction. Polymerase chain reaction. Root canal treatment.

${ }^{1}$ Universidade de São Paulo, Faculdade de Odontologia, São Paulo, SP, Brasil.

¿Universidade de São Paulo, Faculdade de Odontologia, Instituto de Ciências Biomédicas, São Paulo, $\mathrm{SP}$, Brasil. 


\section{Introduction}

Molecular assays targeting ribosomal DNA genes (rDNA) have been extensively used in endodontic microbiology studies. ${ }^{1-9}$ These methods are sensitive, fast, and allow the detection/quantification of endodontic infectious agents. ${ }^{10}$ However, one limitation of the rDNA-based method is the inability to distinguish between live and dead cells, which may result in an overestimation of bacterial targets in root canals, especially in post-treatment samples. ${ }^{11,12}$ Bacterial viability may thus be assessed by molecular methods based on ribosomal RNA (rRNA).

Ribosomal RNA can be considered an indicator of microbial viability because they degrade more rapidly than rDNA after cell death. ${ }^{10}$ Moreover, since the number of ribosomes per cell correlates with bacterial growth rate, rRNA-based methods are considered highly sensitive for detecting active bacterial cells in a community. ${ }^{13-15}$ Since the microbial community profile of root canals comprises many uncultivated bacterial species, rRNA-based molecular methods can be expected to grow in importance as instruments used to monitor viable bacterial loads during endodontic treatment. However, little evidence exists about bacterial activity in endodontic microbial communities using rRNA-based methods. ${ }^{3,15}$

Recently, we have compared the sensitivity of rRNA-based reverse transcription quantitative polymerase chain reaction (RT-qPCR) and rDNA-based qPCR assays for the detection of Enterococcus faecalis in persistent/secondary endodontic infections. ${ }^{15}$ In that study, rRNA-based RT-qPCR was more sensitive than the rDNA-based assay, showing that $E$. faecalis may persist active in treated root canals. ${ }^{15}$ Considering that bacterial species may show differences in their metabolic activity after endodontic treatment procedures, more data are needed on the activity of persistent bacterial species.

Streptococcus species are frequently detected in root canal samples taken after endodontic treatment procedures. ${ }^{2-7}$ Based on our previous study, ${ }^{15}$ we hypothesized that an rRNA-based molecular assay would give a better understanding of cellular viability detection rate of streptococci in root canal samples. Therefore, this study aimed to compare the detection rate of streptococci in root canal samples using rRNAbased RT-PCR and rDNA-based PCR.

\section{Methodology}

\section{Patient selection}

Thirty-two teeth were selected from patients seen at the graduate clinic for root canal treatment. The following inclusion criteria were considered: patients who had asymptomatic teeth with necrotic pulps confirmed by negative responses to pulp sensitivity tests; radiographic evidence of apical periodontitis in single rooted teeth or in one root with a single canal from multi-rooted teeth. Exclusion criteria were also applied, as follows: teeth from patients who had received antibiotics in the previous 3 months or who had any general disease, teeth that could not be properly isolated with rubber dam, non-restored teeth, teeth with periodontal pocket depth $>4 \mathrm{~mm}$; and radiographic evidence of previous endodontic treatment, open apex, crown/root fracture, root resorption, or calcification. This study was conducted in accordance with the Helsinki declaration and was approved by the appropriate Research Ethics Committee (\#428.730). All patients signed an informed consent form prior to starting the study.

\section{Clinical and sampling procedures}

Teeth were isolated with rubber dams, and the operative field was disinfected with $30 \% \mathrm{H}_{2} \mathrm{O}_{2}(\mathrm{v} / \mathrm{v})$ and $2.5 \%$ sodium hypochlorite $(\mathrm{NaOCl})$ for $30 \mathrm{~s}$ each, followed by $5 \%$ sodium thiosulfate to inactivate the disinfecting agents. Access cavities were prepared with sterile high-speed diamond burs irrigated with sterile saline to remove caries and restorations. Before entering the pulp chamber, access cavities were disinfected again, and a bacteriological sample was taken with sterile paper points as a control sample to check the sterility of the disinfected surface. Following, access cavities were completed using new sterile diamond burs. Control samples were placed in cryotubes containing $300 \mu \mathrm{L}$ of RNAlater solution (Life Technologies, Carlsbad, CA, USA) and frozen at $-20^{\circ} \mathrm{C}$ for further DNA extraction. The absence of bacteria in the control sample was verified by PCR using universal primers for the Bacteria domain as previously described. ${ }^{15}$

Following access cavity preparation, the root canal was filled with sterile saline solution, and the working length was established $1.0 \mathrm{~mm}$ short of the apical foramen, using an electronic apex locator (J. Morita Brazil, São Paulo, SP, Brazil). Next, a \#15 H-file was 
pushed against the root canal walls to suspend bacteria into the solution. Five sterile paper points were placed individually inside the root canal for $1 \mathrm{~min}$ each to collect the initial bacteria content (S1). Both the paper points and the $\mathrm{H}$-file, without the handle, were transferred to cryotubes containing $300 \mu \mathrm{L}$ of RNAlater solution (Life Technologies, Carlsbad, CA, USA) and frozen at $-80^{\circ} \mathrm{C}$. In each case, a single root canal was sampled to confine the microbial evaluation to a single ecological environment.

Root canal preparation was performed with R40 or R50 Reciproc instruments (VDW GmbH, Munich, Germany), depending on the initial diameter of the root canal. The selection of instruments to be used followed the manufacturer's instructions. All instruments were used only once and then discarded. Each canal received an initial flush with $10 \mathrm{~mL}$ of $2.5 \%$ $\mathrm{NaOCl}$ delivered by a disposable syringe and 30G side-vented endodontic needles (EndoEZE, Ultradent Products Inc., South Jordan, UT, USA); next, the Reciproc instrument was inserted into the cervical third with an in-and-out pecking motion. If more pressure was needed to advance the instrument further into the canal after one cycle of three in-and-out movements, the file was removed, and its flutes were cleaned. The root canal was irrigated again with $10 \mathrm{~mL}$ of $2.5 \%$ $\mathrm{NaOCl}$, and a new cycle of three in-and-out movements was performed in the middle third, followed by new irrigation. The instrument was inserted up to the working length with a brushing motion against the root canal walls. At the end of the preparation, the canal was irrigated with $10 \mathrm{~mL}$ of $2.5 \% \mathrm{NaOCl}$, for $40 \mathrm{~mL}$ volume in total. The canal was then dried using paper points and flushed with $5 \mathrm{~mL}$ of $5 \%$ sodium thiosulfate for $1 \mathrm{~min}$. Finally, the root canal was filled with sterile saline, and a post-instrumentation sample (S2) was taken as described above.

Following, the root canal was irrigated with $2.5 \%$ $\mathrm{NaOCl}$ and $17 \%$ EDTA, dried using paper points, and filled with Calen paste (S.S. White, Rio de Janeiro, RJ, Brazil), comprised of $\mathrm{Ca}(\mathrm{OH})_{2}$, zinc oxide, colophony (pine resin), and polyethylene glycol 400 . The paste was inserted in the canals using an ML endodontic syringe (S.S. White) attached to a Septojet XL needle (Septodont Brasil Ltda., Barueri, SP, Brazil). Radiographs confirmed proper filling of the root canals with the intracanal medication. Access cavities were filled with $2 \mathrm{~mm}$ of temporary restorative material (Dentalville, Joinville, SC, Brazil) and glass ionomer cement (Vidrion R, S.S. White, Rio de Janeiro, RJ, Brazil).

After 14 days, the tooth was isolated, the temporary restoration removed, and disinfection procedures of the operative field were performed following the same protocol used in the first visit. A new control sample of the dental crown and dentin surrounding the pulp chamber was obtained. The intracanal medication was removed with $10 \mathrm{~mL}$ of $17 \%$ EDTA and agitation with $15 \mathrm{~K}$-files. Then, a third sample (S3) was taken following the same procedures described previously. Completion of the root canal treatment proceeded with root filling using lateral condensation of gutta-percha and $\mathrm{AH}$ Plus sealer (Dentsply Maillefer, Ballaigues, Switzerland). Access cavities were restored with temporary endodontic cement and composite resin (Z350, 3M Corporation, Saint Paul, MN, USA), and a final radiograph was taken.

\section{RNA and DNA extraction}

RNA and DNA extraction was performed with the MasterPure Complete DNA and RNA purification kit (Epicentre Technologies, Madison, WI, USA) according to the manufacturer's instructions. After centrifugation at $10,000 \times g$ for $10 \mathrm{~min}$, supernatants were discarded, and pellets were re-suspended in a solution containing $300 \mu \mathrm{L}$ of tissue and cell lysis solution and $2 \mu \mathrm{L}$ of $50 \mu \mathrm{g} / \mu \mathrm{L}$ proteinase $\mathrm{K}$. After incubation for $15 \mathrm{~min}$ at $65^{\circ} \mathrm{C}$, the mixtures were cooled on ice for $5 \mathrm{~min}$ and added to $200 \mu \mathrm{L}$ of MPC protein precipitation reagent. Following centrifugation at $10,000 \times g$ for 10 min, supernatants were collected and subjected to isopropanol precipitation. Total nucleic acid samples were re-suspended in $35 \mu \mathrm{L}$ of TE buffer and divided in two vials. One vial comprised the total nucleic acid sample, which was used for DNA analysis. In the other vial, DNA was eliminated from total nucleic acid preparation by DNAse treatment and RNA purification was performed following the manufacturer's protocol (Epicentre Technologies, Madison, WI, USA). An additional DNAse treatment was performed using DNase I (Invitrogen Corporation, Carlsbad, CA, USA), and the absence of contaminating DNA in RNA samples was confirmed by PCR. RNA and DNA concentrations were measured using a NanoDrop ND 1000 Spectrophotometer (Thermo Fisher Scientific, Wilmington, DE, USA). DNA was stored at $-20^{\circ} \mathrm{C}$ until use. RT reactions were performed on the same day of extraction. 


\section{Reverse transcription}

The synthesis of complementary DNA (cDNA) was obtained by RT using the SuperScript ${ }^{\circledR}$ III FirstStrand Synthesis System following the manufacturer's instructions (Invitrogen Corporation, Carlsbad, CA, USA). cDNA was synthesized using $8 \mu \mathrm{L}$ of the RNA sample, random hexamers, and cDNA synthesis mix for $20 \mu \mathrm{L}$ in total volume; cDNA was stored at $-20^{\circ} \mathrm{C}$ until use.

\section{PCR}

PCR reactions were performed in $50 \mu \mathrm{L}$ total volume containing 1.25 U Taq DNA polymerase (Perkin-Elmer, Foster City, CA, USA), $5 \mu \mathrm{L} 10 \times$ PCR buffer plus $3 \mathrm{mM}$ $\mathrm{MgCl}_{2}, 1 \mathrm{uM}$ of each primer (Forward 5'-AGA GTT TGA TYM TGG CTC AG-3' and Reverse 5'-TTA GCC GTC CCT TTC TGG T-3') and $0.2 \mathrm{mM}$ (each) deoxynucleoside triphosphates. For each sample, $2 \mu \mathrm{L}$ of DNA or cDNA were added to the reaction mixture. DNA extracted from the Streptococcus mutans strain UA159 was used as positive control, and the reaction mixture without DNA was the negative control. Samples were subjected to 30 cycles of $94^{\circ} \mathrm{C}$ for 1 minute, $55^{\circ} \mathrm{C}$ for 1 minute, and $72^{\circ} \mathrm{C}$ for 2.5 minutes, plus a final $72^{\circ} \mathrm{C}$ extension for 10 minutes. Procedures were conducted in an automated thermal cycler Step One Plus (Applied Biosystems, Foster City, CA, USA). ${ }^{2,16}$

PCR products were analyzed by $1 \%$ agarose gel electrophoresis, stained with ethidium bromide, and viewed under ultraviolet transilluminator light. Positive or negative identification was based on the presence of clear bands of the expected molecular size (502 bp) using a 1-Kb lambda DNA ladder (Invitrogen Corporation, Carlsbad, CA, USA). All assays were repeated, and any cases of disagreement were repeated once again.

\section{Statistical analysis}

McNemar's test was used to compare the detection rates of rRNA- and rDNA-based PCR assays. Intragroup analysis was performed using Fisher's exact test to compare the number of positive PCR reactions for streptococci in the different root canal samples. Differences were considered statistically significant when $P<0.05$.

\section{Results}

All control samples were PCR-negative, which indicated no bacterial contamination. Streptococci were detected in $28.12 \%$ (9/32) and $37.5 \%$ (12/32) of S1 samples using the rRNA- and rDNA-based PCR assays, respectively. In contrast, they were detected in only $6.25 \%(2 / 32)$ of S2 samples using rRNA, compared with $15.62 \%$ (5/32) using rDNA. At the end of treatment (S3), streptococci were not detected by rRNA-based PCR, whereas rDNA was still detected in $12.5 \%$ (4/32) of the samples. Intragroup analysis revealed that the number of positive PCR results significantly decreased after chemomechanical preparation in both rRNA and rDNA groups $(P=0.04$ and $P=0.02$, respectively). However, no significant differences were observed when comparing the number of positive PCR results in S2 and S3 samples (both with $P>0.05$ ) (Table 1 ). Considering all root canal samples, the detection rate obtained by the rDNA-based PCR assay was markedly higher than that obtained by the rRNA-based assay $(P=0.002)$.

\section{Discussion}

Reducing viable bacterial load in root canals is a key element for endodontic treatment success. Because ribosomal RNA ( $r$ RNA) is an indicator of bacterial viability, we used an RT-PCR assay targeting 16S rRNA sequences for the detection of viable streptococci in root canal samples before and after endodontic procedures. Furthermore, we used the rDNA from the same samples as templates for PCR reactions to allow a direct comparison of the two methods. ${ }^{14,15}$ Due to the abundance of ribosomes present in live cells, the rRNA-based method would be expected to be more sensitive to detect viable cells when compared to the

Table 1- Number of positive PCR results for streptococci in samples taken before (S1) and after (S2) root canal preparation, and after calcium hydroxide medication (S3), using rRNA- and rDNA-based PCR assays

\begin{tabular}{cccc}
\hline Samples & S1 & S2 & S3 \\
\hline rRNA & $9 / 32(28.12)^{\mathrm{a}}$ & $2 / 32(6.25)^{\mathrm{b}}$ & $0^{\mathrm{b}}$ \\
rDNA & $12 / 32(37.5)^{\mathrm{a}}$ & $5 / 32(15.62)^{\mathrm{b}}$ & $4 / 32(12.5)^{\mathrm{b}}$ \\
\hline
\end{tabular}

Data presented as number of positive samples/number of samples analyzed (percentages)

Symbols $(a, b)$ indicate that there were significant differences between $\mathrm{S} 1$ and $\mathrm{S} 2$ in both rRNA and rDNA groups (Fisher's signed rank test, $\mathrm{P}<0.05$ ) 
rDNA-based method. ${ }^{13-15}$ However, this study revealed higher streptococci detection frequencies with rDNAbased PCR, suggesting that DNA based methods might have detected non-viable streptococci after endodontic procedures. Our data support previous assertions that DNA from dead bacteria may be a potential confounder in endodontic microbiology studies, as they may overestimate the number of species identified in persistent endodontic infections. ${ }^{17,18}$

The genus Streptococcus was selected for this study because they are frequently found in primary and persistent endodontic infections in rDNAbased molecular studies. ${ }^{3-6,8}$ In this investigation, Streptococcus detection rates were assessed using both rRNA-based RT-PCR and rDNA-based PCR. Before treatment (S1 samples), detection frequencies were similar using both methods, except for three cases in which streptococcus rRNA could not be detected in rDNA-positive samples, indicating that these organisms are usually active in the microbial community of primary endodontic infections. The rRNA-negative and rDNA-positive samples before treatment suggest that streptococci may have participated in the early stages of infection in these cases, but were not active at the moment of root canal sampling. Our findings corroborate previous in vitro data that showed that DNA may persist in infected teeth after bacterial death. ${ }^{11,17,18}$ The high binding affinity between DNA and hydroxyapatite/dentin has been shown to make it less susceptible to degradation by serum and nucleases, contributing to long-term persistence of DNA in teeth. ${ }^{11}$

Following chemomechanical preparation (S2 samples), Streptococcus rDNA was detected in $5 / 32$ canals $(15.62 \%)$, which is comparable to the prevalence reported by previous rDNA-based molecular studies. ${ }^{2,4,5}$ However, most samples in this study that tested positive in the rDNA-based PCR assay resulted negative in the rRNA-based analysis. Our findings confirm that the detection of DNA from recently dead microbial cells may hinder a reliable analysis of antimicrobial treatment effects when using DNA-based molecular methods. ${ }^{17}$

The PCR detection rate in this study was higher than that of RT-PCR. This finding is in contrast with our previous study, in which the rRNA-based molecular assay was more sensitive to detect $E$. faecalis in root canals. ${ }^{15}$ The differences between the two studies may be related to the molecular methods used for nucleic acid detection. In our previous study, the use of RT-qPCR may have allowed the detection of low rRNA levels, leading to an increased detection rate of $E$. faecalis by that method. Moreover, the discrepancy between the present findings for streptococci when compared to our previous findings for $E$. faecalis may reflect differences in bacterial susceptibility to endodontic treatment procedures. The higher detection rate of $E$. faecalis by rRNA-based methods may be a consequence of higher amounts of viable $E$. faecalis in post-treatment samples due its resistance to endodontic procedures. Since the status of bacterial species after treatment may range from inactive/dead cells to cells with high metabolic activity, the use of rRNA-based molecular methods would be advantageous to elucidate the potential etiological agents of persistent endodontic infections. This method would be even more relevant in studies assessing the viability of uncultivated or difficult-toculture bacterial species.

One limitation of this study was the use of molecular assays that did not allow a quantitative analysis of streptococci cells present in root canal samples. The viable bacterial load persisting after endodontic procedures may impact treatment outcomes. ${ }^{19}$ Therefore, the use of quantitative molecular methods would be imperative in endodontic microbiology studies. Because the absolute number of bacterial cells is related to the number of rRNA genes, new strategies have been investigated to overcome the limitation of rDNA-based assays in detecting dead bacterial cells. One of those strategies is the use of propidium monoazide (PMA) coupled with qPCR (PMA-qPCR). 12,20 However, the detection limit of PMA-qPCR assays $\left(10^{3}\right.$ $\mathrm{CFU} / \mathrm{mL}$ ) may impair their use in molecular studies assessing the antimicrobial efficacy of endodontic procedures. ${ }^{12,20}$ In this sense, an important strategy to obtain information on both bacterial viability and number of bacterial cells in endodontic samples would be the association of rRNA- and rDNA-based qPCR assays, as previously demonstrated. ${ }^{15}$

\section{Conclusion}

In summary, our study revealed differences in the detection frequency of streptococci using rRNA-based RT-PCR and rDNA-based PCR. Compared to rRNAbased RT-PCR, the rDNA-based PCR assay showed a higher detection rate of streptococci. This finding 
confirmed previous studies, suggesting that DNA detection may not always be associated with active endodontic infection. Therefore, rRNA-based methods may be more suitable to identify functional bacteria that effectively contribute to persistent endodontic infections.

\section{Acknowledgments}

This research was funded by São Paulo Research Foundation (FAPESP; grants no. 2013/02923-9, 2016/15473-0) and CAPES. The sponsor did not have any role in study design, collection, analysis and interpretation of data, writing of the report, or the decision to submit the article for publication.

The authors deny any conflicts of interest related to this study.

\section{References}

1- Siqueira JF, Rôças IN. Diversity of endodontic microbiota revisited. J Dent Res. 2009;88(11):969-81.

2- Rôças IN, Siqueira JF. Characterization of microbiota of root canal-treated teeth with posttreatment disease. J Clin Microbiol. 2012;50(5):1721-4

3- Rôças IN, Siqueira JF Jr. Identification of bacteria enduring endodontic treatment procedures by a combined reverse transcriptasepolymerase chain reaction and reverse-capture checkerboard approach. J Endod. 2010;36(1):45-52.

4- Neves MA, Rôças IN, Siqueira JF. Clinical antibacterial effectiveness of the self-adjusting file system. Int Endod J. 2014;47(4):356-65.

5- Rôças IN, Siqueira JF Jr. In vivo antimicrobial effects of endodontic treatment procedures as assessed by molecular microbiologic techniques. J Endod. 2011;37(3):304-10.

6- Sakamoto M, Siqueira JF Jr, Rôças IN, Benno Y. Bacterial reduction and persistence after endodontic treatment procedures. Oral Microbio Immunol. 2007;22(1):19-23.

7- Rôças IN, Provenzano JC, Neves MA, Siqueira JF Jr. Disinfecting effects of rotary instrumentation with either $2.5 \%$ sodium hypochlorite or $2 \%$ chlorhexidine as the main irrigant: a randomized clinical study. J Endod. 2016;42(6):943-7.
8- Siqueira JF Jr, Rôças IN, Paiva SS, Guimarães-Pinto T, Magalhães KM, Lima KC. Bacteriologic investigation of the effects of sodium hypochlorite and chlorhexidine during the endodontic treatment of teeth with apical periodontitis. Oral Surg Oral Med Oral Pathol Oral Radiol Endod. 2007;104(1):122-30.

9- Siqueira JF Jr, Magalhães KM, Rôças IN. Bacterial reduction in infected root canals treated with $2.5 \% \mathrm{NaOCl}$ as an irrigant and calcium hydroxide/camphorated paramonochlorophenol paste as an intracanal dressing. J Endod. 2007;33(6):667-72

10- Siqueira JF, Rôças IN. Exploiting molecular methods to explore endodontic infections: Part 1 - current molecular technologies for microbiological diagnosis. J Endod. 2005;31(6):411-23.

11- Brundin M, Figdor D, Sundqvist G, Sjögren U. DNA binding to hydroxyapatite: a potential mechanism for preservation of microbial DNA. J Endod. 2013;39(2):211-6.

12- Pinheiro ET, Neves VD, Reis CC, Longo PL, Mayer MP. Evaluation of the propidium monoazide-quantitative polymerase chain reaction method for the detection of viable Enterococcus faecalis. J Endod. 2016;42(7):1089-92.

13- Matsuda K, Tsuji H, Asahara T, Kado $Y$, Nomoto K. Sensitive quantitative detection of commensal bacteria by rRNA-targeted reverse transcription-PCR. Appl Environ Microbiol. 2007;73(1):32-9.

14- Pitkänen T, Ryu H, Elk M, Hokajärvi AM, Siponen S, Vepsäläinen $A$, et al. Detection of fecal bacteria and source tracking identifiers in environmental waters using rRNA-based RT-qPCR and rDNA-based qPCR assays. Environ Sci Technol. 2013;47(23):13611-20.

15- Pinheiro ET, Candeiro GT, Teixeira SR, Shin RC, Prado LC, Gavini G, et al. RNA-based assay demonstrated Enterococcus faecalis metabolic activity after chemomechanical procedures. J Endod. 2015;41(9):1441-4

16- Rôças IN, Hülsmann M, Siqueira JF Jr. Microorganisms in root canaltreated teeth from a German population. J Endod. 2008;34(8):926-31. 17- Brundin M, Figdor D, Sundqvist G, Sjögren U. Preservation of Fusobacterium nucleatum and Peptostreptococcus anaerobius DNA after loss of cell viability. Int Endod J. 2015;48(1):37-45

18- Brundin M, Figdor D, Roth C, Davies JK, Sundqvist G, Sjögren $U$. Persistence of dead-cell bacterial DNA in ex vivo root canals and influence of nucleases on DNA decay in vitro. Oral Surg Oral Med Oral Pathol Oral Radiol Endod. 2010;110(6):789-94.

19- Siqueira JF, Rôças IN. Clinical implications and microbiology of bacterial persistence after treatment procedures. J Endod. 2008;34(11):1291-301.e3.

20- Loozen G, Boon N, Pauwels M, Quirynen M, Teughels W. Live/dead real-time polymerase chain reaction to assess new therapies against dental plaque-related pathologies. Mol Oral Microbiol. 2011;26(4):25361. 